\section{Woody Award Goes to Gordon E. Pike}

Outgoing MRS president Jim Roberto presented the MRS Woody Award to Gordon Pike for sustained outstanding commitment and exceptional service to the Materials Research Society for many years. "Pike has provided uniquely broad and effective leadership in almost every aspect of the Society," said Roberto.

After serving as a symposium organizer for the 1981 MRS Fall Meeting, Pike cochaired the 1983 Fall Meeting, and then became the lead co-chair of the group that implemented the first MRS Spring Meeting, a spin-off from the 1983 MRS Fall Meeting

Pike was elected MRS president in 1986 , serving on the executive committee from 1985 through 1987, and as a councillor from 1989 through 1991. He has been a member of most MRS committees and has chaired the Program, Awards, Nominating, External Affairs, and Long-Range Planning Committees.

He has been especially active in the External Affairs Committee, which he now chairs. In facilitating MRS's interaction with other organizations, Pike developed a set of procedures and policy guidelines for co-sponsoring meetings, and he intro- duced the concept of meeting endorsement. He also created the affiliated organizations program to strengthen ties with other organizations that share common interests with MRS.

Pike provided the impetus to structure and catalogue the mailing list database at MRS headquarters. Now including over 120,000 names, the database can successfully match suppliers of information, materials, and equipment with potential users in the materials community. The categories that Pike compiled with the help of many volunteers are now called the "Pike codes."

Pike holds a BS in physics from Carnegie Mellon University and a PhD in physics from the University of Pittsburgh. He is currently acting manager of the Chemistry and Ceramics Department at Sandia National Laboratories, Albuquerque, New Mexico. His research contributions at Sandia span electronic properties of semiconductor grain boundaries, conduction in insulators, transport properties in heterogeneous materials, and processingproperty relationships of superconducting films on carbon fibers.

The Woody Award is given informally to recognize outstanding volunteer service to

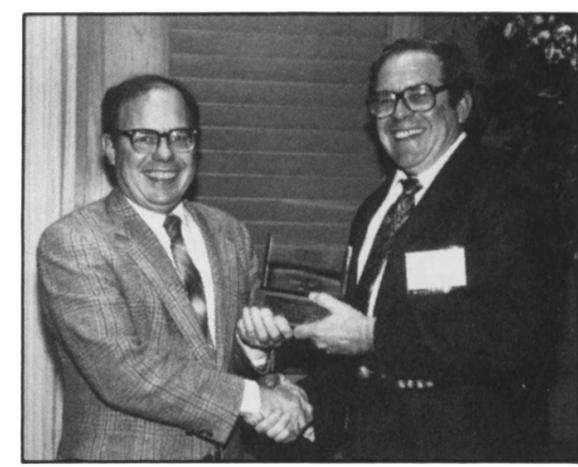

Gordon Pike (left), the most recent recipient of the Woody Award, is congratulated by its first recipient, Woody White.

MRS above and beyond normal expectations which has contributed to the success of the Materials Research Society. The name comes from the accomplishments achieved by C. W. "Woody" White during his MRS presidency in 1984. The award was presented to Pike at the MRS Council dinner during the 1991 MRS Fall Meeting in Boston.

\title{
'92 MRS Spring Meeting Introduces Five New Short Courses and Tutorial
}

As part of an ongoing effort to keep the MRS Short Course Program relevant and useful to the materials community, the 1992 MRS Spring Meeting will introduce five new short courses and a tutorial. The tutorial, Introduction to Parallel Supercomputing in Materials Science (TP-1), features an experimental format. The new, half-day presentation, shorter than other courses, is intended to be a tightly focused prelude and complement to a specific symposium. Tutorial TP-1 complements Symposium W, Computational Methods in Materials Science, and will be offered immediately before the start of the symposium.

Of the other five courses, one is completely new and the other four are updated or revised versions of existing courses. Two courses focus on characterization and three on preparation and fabrication of materials.

Automated spectroscopic ellipsometry has recently emerged as an important technique for fast, accurate, nondestructive measurement of layer thickness, refractive index, and composition. Materials Research and Analysis Using In-Situ and ExSitu Spectroscopic Ellipsometry (C-27), a new course, covers the use of spectroscopic ellipsometry for analysis of a variety of layers, including multilayers of semiconductors and dielectrics, optical coatings, and beam-modified surfaces.

Scanning Electron Microscopy: Applications to Electronic Materials and Devices (C-16) is an introduction to SEM and electron probe microanalysis, with emphasis on examining semiconductors, metals, and insulators used in modern electronic devices.

Materials and Processing Aspects of Advanced VLSI Assembly and Packaging (F04) covers design and manufacturability issues associated with advanced VLSI packaging, and addresses how materials and processing affect production yields and product reliability.

Materials and Processes at the Leading Edge of Microlithography (F-11) describes the materials and process aspects of micro- lithography for UV, x-ray, e-beam, and ion beam sources. In each case, the role of the resist and its processing is analyzed and critical judgments are made concerning the state of the art.

Vapor Phase Synthesis of Powders and Films (P-17) gives an overview of the different techniques for vapor phase processing of films and powders. Specific examples for production of oxides and metals such as films of $\mathrm{Cu}$ and $\mathrm{YBa}_{2} \mathrm{Cu}_{3} \mathrm{O}_{7}$, and powders of $\mathrm{TiO}_{2}, \mathrm{BaTiO}_{3}$, and $\mathrm{YBa}_{2}-$ $\mathrm{Cu}_{3} \mathrm{O}_{7}$ are outlined.

For more details about these courses or the other 12 courses being offered at the Spring 1992 Meeting, contact: Vivienne Harwood Mattox, MRS Short Course Manager (B); phone (505) 294-9532; fax (505) 2987942.

See p. 57 in this issue for a list of short courses being offered at the 1992 MRS Spring Meeting in San Francisco.

R.N. Sacks

MRS Continuing Education Committee 